\title{
EXPERIMENTAL EVALUATION OF THE ANTI-ULCER ACTIVITY OF GRAPE (VITIS VINIFERA) SEED EXTRACT IN WISTAR ALBINO RATS AGAINST HYDROCHLORIC ACID - ETHANOL-INDUCED ULCER MODEL
}

\author{
ANAND M INGALE ${ }^{1 *}$, VENKATA BHARATKUMAR PINNELLI², VIJAYA RAJENDRAN ${ }^{1}$ \\ ${ }^{1}$ Department of Pharmacology, Vydehi Institute of Medical Sciences and Research Centre, Nallurhalli, Whitefield, Bengaluru - 560066 , \\ Karnataka, India. ${ }^{2}$ Department of Biochemistry, Vydehi Institute of Medical Sciences and Research Centre, Nallurhalli, Whitefield, \\ Bengaluru - 560 066, Karnataka, India. Email: dr.anandingale@gmail.com
} Received: 01 September 2016, Revised and Accepted: 15 September 2016

\section{ABSTRACT}

Objectives: To evaluate the antiulcer activity of ethanolic extract of seeds of (grape) Vitis vinifera in Wistar albino rats.

Methods: The ethanolic extract of $V$. vinifera was investigated for its antiulcer activity in Wistar albino rats against hydrochloric acid - ethanolinduced ulcer model. The antiulcer activity was assessed by determining and comparing the gastric volume, $\mathrm{pH}$, free, and total acidity; ulcer number and its inhibition, ulcer severity, and ulcer index.

Results: A significant antiulcer activity was observed. The grape seed $100 \mathrm{mg} / \mathrm{kg}$ group showed significant $(\mathrm{p}<0.05)$ reduction in ulcer number as compared to the control. The grape seed $200 \mathrm{mg} / \mathrm{kg}$ showed significant $(\mathrm{p}<0.05)$ reduction in ulcer number, free acidity, and gastric lesion as compared to the control.

Conclusion: This study indicates that $V$. vinifera seed extract has potential antiulcer activity in the model tested.

Keywords: Vitis vinifera, Anti-ulcer, Ethanol, Free acidity, Total acidity.

(c) 2016 The Authors. Published by Innovare Academic Sciences Pvt Ltd. This is an open access article under the CC BY license (http://creativecommons. org/licenses/by/4. 0/) DOI: http://dx.doi.org/10.22159/ajpcr.2016.v9i6.14999

\section{INTRODUCTION}

Peptic ulcer disease, whose incidence is gradually increasing on account of the changing lifestyle and stress among people, is a common disease [1] of the present day life affecting numerous people worldwide with a male preponderance [2].

In spite of many drugs being available for the management of this common clinical condition, herbal products [3] are finding an important place in its therapy on account of their better safety and efficacy profile [4]

Grapes are among the most easily cultivated and available plants worldwide. Different parts of the grape plant have proven medical application [5] in Ayurveda. Grape seed, which is a waste product of winery, has also been proved to have various therapeutic applications.

Grape seed is a very rich source of antioxidants [6]. It possesses antibacterial effects against Helicobacter pylori [7] and methicillinresistant Staphylococcus auerus [8]. It is proven to have antiinflammatory action [9]; cardiovascular and endothelial protection activity [10]; anti-hepatotoxic action [11]; adaptogenic and nootropic effects [12]; platelet function [13]; apoptosis [14] and aromatase inhibitor action [15]; vascular endothelial growth factor and angiogenesis inhibition activity [16]; antiviral and antifungal properties. Most of the activities of grape seed extract (GSE) are attributed to its antioxidant activity. GSE is shown to have antiulcer activity [17], effect on ethanol [18], and stress-induced gastric lesions.

This study is hereby undertaken to evaluate the antiulcer activity of GSE against hydrochloric acid $(\mathrm{HCl})$ - ethanol-induced gastric ulcer mode in Wistar albino rats, which will determine the possible cytoprotective property of the extract.

Establishment of the antiulcer activity of GSE may provide a newer and economically better modality of the treatment for peptic ulcer, which may have a better safety and efficacy.

\section{METHODS}

This study was conducted only after being approved by Committee for the Purpose of Control and Supervision of Experimental Animals (CPCSEA) on 30.08.2012. The CPCSEA Guidelines were meticulously and strictly followed throughout the study.

\section{Procedure of GSE}

Grape seeds were removed from the grapes and air dried for 1 week $100 \mathrm{~g}$ of dried seeds were soaked in $300 \mathrm{ml}$ of ethanol (95\%) with occasional stirring for $24 \mathrm{hrs}$ and filtered using a piece of filter cloth The residue of grape seeds was soaked in $300 \mathrm{ml}$ ethanol (95\%), and the above procedure was repeated twice. The entire fluid was collected and concentrated at $500^{\circ} \mathrm{C}$ with vacuum in rotary evaporator (Fig. 1)

Fig. 1 shows the ethanolic extract of GSE employed in this study.

\section{Animals}

In-bred Wistar albino rats (Rattus norvegicus) of either sex weighing 150-250 g, acclimatized to the laboratory conditions for 2 weeks with a $12 \mathrm{hrs} \mathrm{light} \mathrm{and} \mathrm{dark} \mathrm{cycle,} \mathrm{were} \mathrm{used} \mathrm{for} \mathrm{this} \mathrm{study.} \mathrm{All} \mathrm{experiments}$ were performed during the same time of the day to avoid diurnal variations of gastric functions.

\section{Drugs and chemicals}

All the chemicals used in this evaluation were of high grade and purity.

- Sucralfate powder (Fourrts India Ltd)

- Topfers reagent (Merck \& Co.)

- Phenolphthalein indicator, sodium hydroxide $(\mathrm{NaOH})(0.01 \mathrm{~N})(\mathrm{S} . \mathrm{D}$. Fine Chem. Ltd).

\section{Procedure of $\mathrm{HCl}$ - ethanol model}

The procedure was followed according to Saito et al. [19] healthy Wistar albino rats of either sex; weighing 150-200 g was included in this study. The rats were fasted (water allowed) for 1 day. They were divided into four groups of six rats each as follows: 
- Group 1 (Control): Received $1 \mathrm{ml}$ distilled water orally

- Group 2 (Standard): Treated with standard (100 mg/kg sucralfate) orally

- $\quad$ Group 3 (GSE 100): Treated with $100 \mathrm{mg} / \mathrm{kg}$ of GSE orally

- Group 4 (GSE 200): Treated with $200 \mathrm{mg} / \mathrm{kg}$ of GSE orally

The rats were fasted (water allowed) for 1 day. On the next day, respective test compounds (distilled water, GSE $100 \mathrm{mg} / \mathrm{kg}$, GSE $200 \mathrm{mg} / \mathrm{kg}$ ) were given. After 30 minutes of dosing, $1 \mathrm{ml} 0.3 \mathrm{M} \mathrm{HCl}$ and $60 \%$ ethanol was administered orally. $1 \mathrm{hr}$ later, the rats were sacrificed by cervical dislocation.

The stomach was excised after tying both the ends of stomach. The gastric contents were drained into centrifuge tube and analyzed.

\section{pH and gastric volume analysis}

The contents of the stomach obtained were drained into the centrifuge tube and centrifuged at the speed of 1000 revolutions per minute for 20 minutes. The supernatant fluid obtained was collected and its volume was estimated. The $\mathrm{pH}$ of the content was noted using $\mathrm{pH}$ strips by matching the color obtained with that of the reference standard [20]

\section{Free and total acidity analysis}

The gastric content obtained was diluted to $10 \mathrm{ml}$ by adding distilled water and analyzed for its free and total acidity by titrating it against $0.01 \mathrm{~N} \mathrm{NaOH}$ solution using topfers reagent (dimethylaminoazobenzene in $95 \%$ alcohol) and phenolphthalein as indicators [21].

\section{Ulcer number estimation}

The gastric mucosa was observed macroscopically under $\times 10$ magnifications and the number of superficial ulcers, deep ulcers, and perforations were noted [22].

\section{Gastric lesion estimation}

Gastric lesion of all possible ulcers was recorded by measuring its longest diameter (in $\mathrm{mm}$ ) by means of divider and graph paper. Total gastric lesion in each rat was calculated [23].

\section{Ulcer severity estimation}

The ulcers in each rat were graded as:

- 0 - No ulcers,

- 1 - Superficial ulcers,

- 2 - Deep ulcers,

- 3 - Perforations

Average severity score of each group was calculated [24].

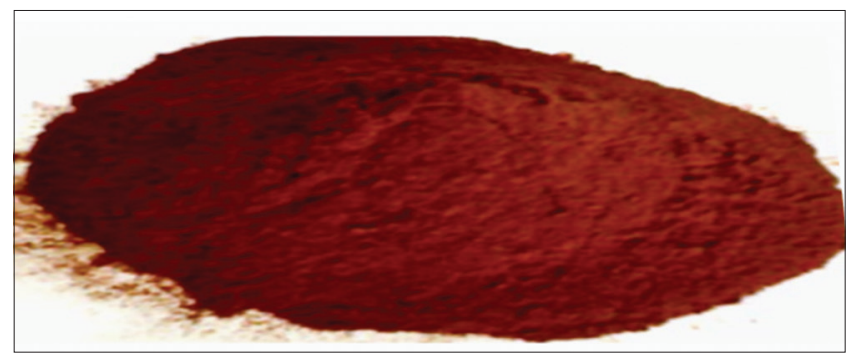

Fig. 1: Grape seed extract

\section{Ulcer index estimation}

Ulcer index in each group was calculated by the formula [25]: UI = UN $+\mathrm{US}+\mathrm{UP}^{*} 10^{-1}$

Where, UI = Ulcer Index; UN = Average of number of ulcer per animal;

US = Average of severity score and UP = Percentage of animal with ulcer.

\section{Statistical analysis}

The data were expressed as mean \pm standard error of mean. Results were analyzed statistically by one-way analysis of variance followed by Dunnett's t-test using standard statistical Software Package of Social Science version 20. All the groups were compared with the control group. The difference was considered significant if $\mathrm{p}<0.05$.

\section{RESULTS}

In the $\mathrm{HCl}$ - ethanol model, the study with standard (sucralfate $100 \mathrm{mg} / \mathrm{kg} / \mathrm{p}$. o. $)$ showed significant $(\mathrm{p}<0.05)$ reduction in free acidity (Table 1), ulcer number $24.00 \pm 3.7$ (Fig. 3), and gastric lesion $16.67 \pm 2.1$ (Fig. 4) as compared to the control. There was no significant change in the gastric volume, $\mathrm{pH}$, total acidity, and bound acidity (Table 1).

The grape seed $100 \mathrm{mg} / \mathrm{kg}$ group showed significant $(\mathrm{p}<0.05)$ reduction in ulcer number $30.00 \pm 3.23$ (Fig. 3 ) when compared with the control group. There was no significant change in the gastric volume, $\mathrm{pH}$, free acidity, total acidity, bound acidity (Table 1 ), and gastric lesion $23.00 \pm 4.69$ (Fig. 4).

The grape seed $200 \mathrm{mg} / \mathrm{kg}$ showed significant $(\mathrm{p}<0.05)$ reduction in free acidity (Table 1) ulcer number 27.33 \pm 2.97 (Fig. 3) and gastric lesion $18.00 \pm 2.96$ (Fig. 4) when compared with the control group. There was no significant change in the gastric volume, $\mathrm{pH}$, total acidity, and bound acidity (Table 1).

The ulcer inhibition was $42.39 \%, 27.98 \%$ and $34.67 \%$, respectively, with the standard, $100 \mathrm{mg} / \mathrm{kg}$ group and $200 \mathrm{mg} / \mathrm{kg}$ group (Fig. 3).

The ulcer protection was $25 \%, 10.4 \%$ and $18.06 \%$, respectively, with the standard, $100 \mathrm{mg} / \mathrm{kg}$ group and $200 \mathrm{mg} / \mathrm{kg}$ group (Fig. 6).

The gastric mucosa of the rats in the model tested is shown in Fig. 2.

\section{DISCUSSION}

In this model, ethanol, which is an alcohol, produced its action by having a direct erosive irritant effect on the gastric mucosa. It causes significant production of oxygen free radicals leading to increased lipid peroxidation, causing damage to the cell and cell membrane [26]. Ethanol may also cause depletion of gastric mucus content, damaged mucosal blood flow and mucosal cell injury causing an imbalance between the aggressive and defensive factors governing the gastric mucosa resulting in increased vascular permeability, edema formation, and epithelial lifting. Ethanol is metabolized in the body releasing superoxide anion and hydroperoxy free radicals which are involved in the mechanism of acute and chronic ulceration in the gastric mucosa [27].

$\mathrm{HCl}$ also brings about its effect by having a direct irritant property on the gastric mucosa by causing necrotic lesions on the gastric mucosa [19].

Table 1: Effect of the ethanolic extract of GSE on gastric content parameters in the $\mathrm{HCl}$ - ethanol ulcer model

\begin{tabular}{llll}
\hline & Control (1 ml) & Standard (mg/kg/p.o.) & GSE 100 (mg/kg/p.o.) \\
\hline Gastric volume (in ml/kg) & $0.16 \pm 0.00$ & $0.10 \pm 0.01$ & $0.18 \pm 0.01$ \\
pH & $1.00 \pm 0.0$ & $1.5 \pm 0.22$ & $1.00 \pm 0.00$ \\
Free acidity (in mEq/L/100 g) & $28.33 \pm 1.17$ & $18.83 \pm 3.14^{*}$ & $26.66 \pm 0.84$ \\
Total acidity (in mEq/L/100 g) & $48.33 \pm 2.15$ & $37.00 \pm 4.06$ & $54.16 \pm 3.82$ \\
\hline
\end{tabular}

All the values are expressed as mean \pm SEM; $n=6$. Statistical significance: * $<<0.05$. One-way ANOVA followed by Dunnett's test. SEM: Standard error of mean, GSE: Ethanolic extract of grape seed extract, ANOVA: Analysis of variance, HCl: Hydrochloric acid 


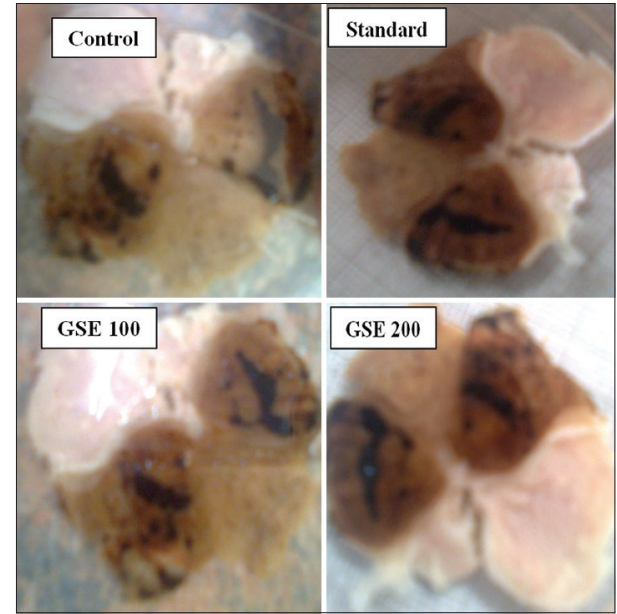

Fig. 2: Stomach mucosa of rats of various groups in the hydrochloric acid - ethanol model

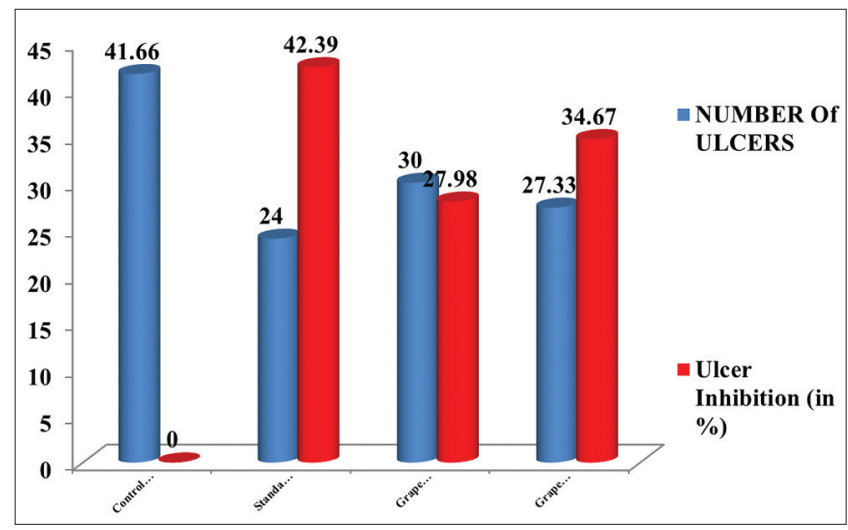

Fig. 3: Effect of the ethanolic extract of grape seed extract on number of ulcers and ulcer inhibition in the hydrochloric acid ethanol ulcer model. $n=6$ in all groups

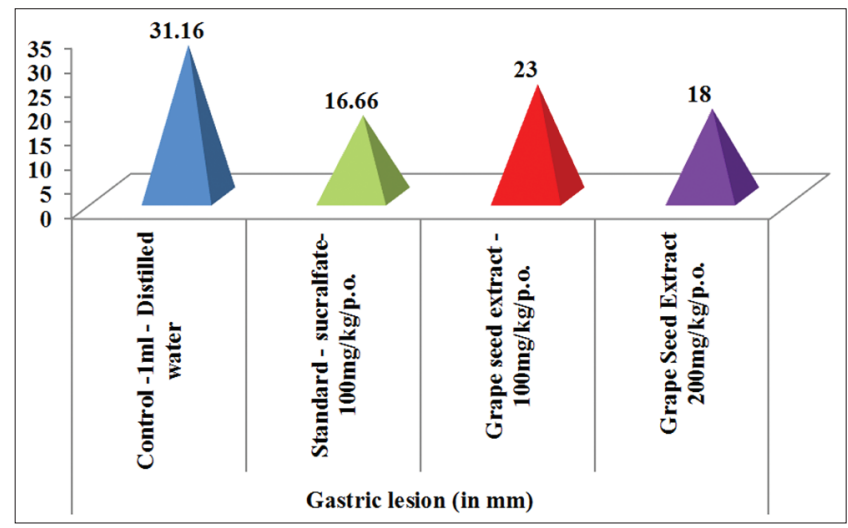

Fig. 4: Effect of the ethanolic extract of grape seed extract on gastric lesion in the hydrochloric acid - ethanol ulcer model. $n=6$ in all groups

Administration of $\mathrm{HCl}$ and ethanol produced ulcerative lesions in the gastric mucosa on account of their synergistic actions.

This study showed a decrease in the gastric volume in the standard groups and its increase in the grape seed 100 group and grape seed 200 group when compared with the control group, but they were not significant. The increase in the gastric content production could be due to the compensatory mechanisms acting in the mucosa to overcome

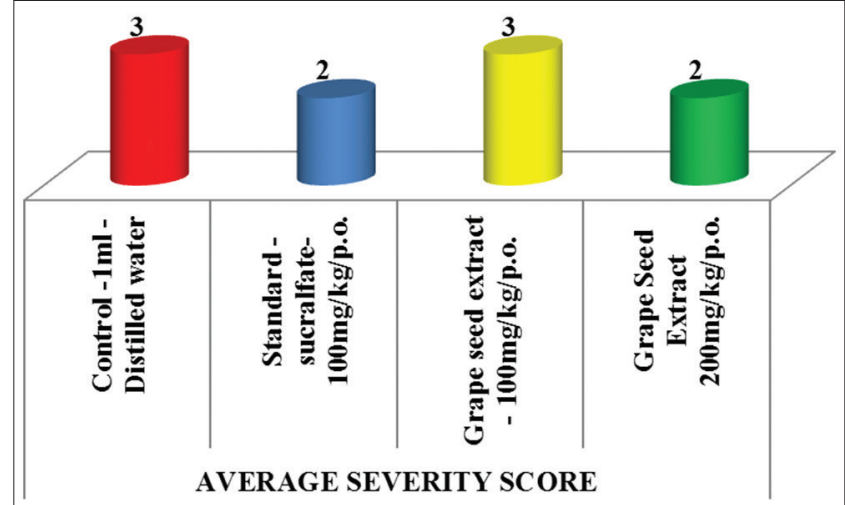

Fig. 5: Effect of the ethanolic extract of grape seed extract on average severity score in the hydrochloric acid - ethanol ulcer model. $n=6$ in all groups

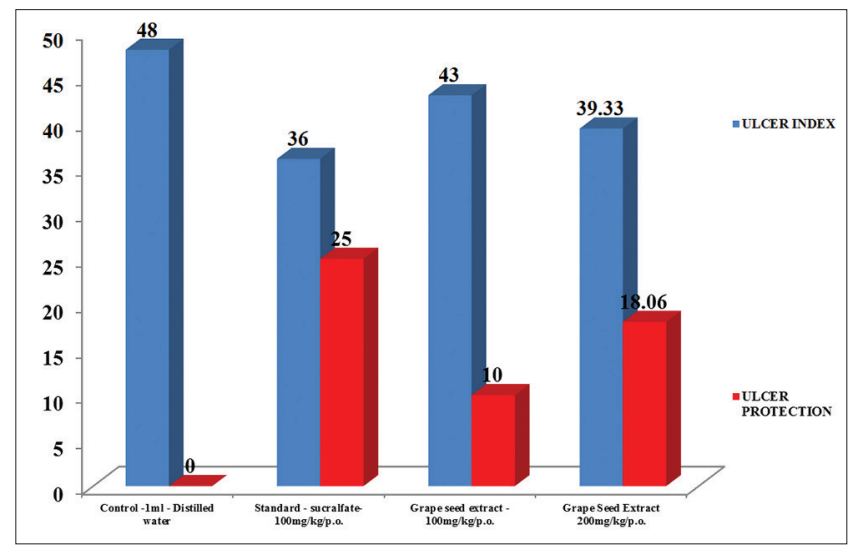

Fig. 6: Effect of the ethanolic extract of grape seed extract on ulcer index and ulcer protection in the hydrochloric acid - ethanol ulcer model. $n=6$ in all groups

the acidic environment in the stomach. As the rise was not significant, the result cannot be authenticated and could be a result of biological variations among individuals. The data can be better confirmed by seeing the effect on gastric volume on a larger study population.

As the $\mathrm{pH}$ was noted using $\mathrm{pH}$ strips colorimetrically by comparing with the reference standard, the accurate recording of the $\mathrm{pH}$ could not be done. The $\mathrm{pH}$ could have been accurately estimated using $\mathrm{pH}$ meter.

The results of free and total acidity point out that higher concentration of the extract possessing higher proanthocyanidin content [28] exert better effect in decreasing the acidity. The antioxidant activity of the extract abolishes the genesis of oxidative stress, causing reversal of oxidative activities and having a beneficial role in the gastric mucosa.

The number of ulcers was significantly decreased in the grape seed $100 \mathrm{mg} / \mathrm{kg}$ group and $200 \mathrm{mg} / \mathrm{kg}$ group when compared with the control group. As a result of change in the gastric volume and increase in the acidity, the ulcer number was consequently reduced. Antioxidant activity [6] of the extract reverses the oxidative stress and inhibits reactive oxygen species to have a protective role on the gastric mucosa. The percentage decrease in the number of ulcers with grape seed $100 \mathrm{mg} / \mathrm{kg}$ group was $27.98 \%$ and with grape seed $200 \mathrm{mg} / \mathrm{kg}$ group was $34.67 \%$ when compared with the control group.

The gastric lesion was significantly reduced in the grape seed $200 \mathrm{mg} / \mathrm{kg}$ group on account of higher antioxidant activity [29] exerted by the high proanthocyanidins content possessing antioxidant actions. 
A significant decrease in the ulcer severity was seen in grape seed $200 \mathrm{mg} / \mathrm{kg}$ group that possesses higher polyphenol content.

The study of the effect on gastric lesions by GSE by employing ethanol was done by in 2005 [30]. They evaluated the gastric defense mechanism of grapefruit seed extract against ethanol and stressinduced gastric lesions in male Wistar rats by inducing gastric mucosal lesions by $100 \%$ ethanol or 3.5 hrs of water immersion stress. Their study showed a significant fall in the gastric blood flow and superoxide dismutase activity and rise in the mucosal malondialdehyde (MDA) content. Pretreatment with GSE caused a dose dependent attenuation of gastric lesions and, the dose reducing these lesions by $50 \%$ was 25 and $36 \mathrm{mg} / \mathrm{kg}$ respectively. The study showed GSE exerting a potent gastroprotective activity through an increase in endogenous prostaglandin generation, suppression of lipid peroxidation, and hyperemia. The results obtained in this study do not correlate to the study quoted above. The reasons for this can be the higher concentration $(100 \%)$ of ethanol being used, and also the different parameters analyzed in their study.

In another study done in 2011 [31], the effects of GSE, vitamin C (VC), and vitamin $\mathrm{E}$ (VE) on ethanol and aspirin-induced ulcers were evaluated. Oral administration of GSE, VC, and VE at 25 and $250 \mathrm{mg} / \mathrm{kg}$ prevented gastric mucosal ulceration and reduced the increase of gastric MDA elicited by these aggressive agents. GSE 25 and $250 \mathrm{mg} / \mathrm{kg}$ produced greater reduction of ethanol than aspirin-induced ulcers. GSE prevented ethanol-induced gastric ulcers more effectively than VC or VE, while its protection against aspirin ulcers was comparable for all treatments. GSE produced the greatest reductions of gastric MDA in both models. The gastroprotective effect of GSE is proportional to its ability of reducing lipid peroxidation in the gastric mucosa. The results obtained in this study do not correlate to the above-quoted study on account of the different species of rats used, and also the different dose employed in their study. Levels of MDA were analyzed, which was not done in this study.

\section{CONCLUSION}

This study concludes that the ethanolic extract of GSE has antiulcer activity in the model employed. It has an antiulcer activity comparable to that of the standard drug.

GSE of $200 \mathrm{mg} / \mathrm{kg}$ dose possesses a better effect on all the parameters analyzed than that of $100 \mathrm{mg} / \mathrm{kg}$ dose. There was no significant change in the parameters except the number of ulcers, gastric lesion, and free acidity in the $\mathrm{HCl}$ - ethanol model.

The results can be more accurately assessed by either involving a larger sample size or using a higher concentration of the extract.

\section{ACKNOWLEDGMENTS}

The authors gratefully acknowledge the Director of Vydehi Institute of Medical Sciences and Research Centre, Whitefield, Bangalore, for their kind support throughout the study. We extend our thanks to Olive Life Sciences, Bengaluru, for providing the grape seed extract.

\section{REFERENCES}

1. Muchandi AA, Chandrashekhar VM. Antiulcer and gastroprotective potential of Stereospermum suaveolens in wistar rats. J Pharmacol Pharmacother 2011;2(2):117-9.

2. Sharma MP, Ahuja V. Peptic ulcer disease and non ulcer dyspepsia. In: Tandon BN, editor. Tropical Hepato-Gastroenterology. New Delhi: Elsevier Publishers; 2008. p. 97-115.

3. Department of Pharmacology and Therapeutics. Herbal medicines An evidence based look. Canada: The University of British Columbia; 1998.

4. World Health Organization. Policy Perspectives on Medicines Traditional Medicine - Growing Needs and Potential. Vol. 2. Geneva: World Health Organization; 2002.

5. Vaughan JG, Geissler CA. The New Oxford Book of Food Plants.
New York: Oxford University Press; 1997.

6. Ahn HS, Jeon TI, Lee JY, Hwang SG, Lim Y, Park DK. Antioxidative activity of persimmon and grape seed extract: In vitro and in vivo. Nutr Res 2002;22(11):1265-73.

7. Brown JC, Huang G, Haley-Zitlin V, Jiang X. Antibacterial effects of grape extracts on Helicobacter pylori. Appl Environ Microbiol 2009;75(3):848-52.

8. Al-Habib A, Al-Saleh E, Safer AM, Afzal M. Bactericidal effect of grape seed extract on methicillin-resistant Staphylococcus aureus (MRSA). J Toxicol Sci 2010;35(3):357-64

9. Zayachkivska OS, Konturek SJ, Drozdowicz D, Konturek PC, Brzozowski T, Ghegotsky MR. Gastroprotective effects of flavonoids in plant extracts. J Physiol Pharmacol 2005;56 Suppl 1:219-31.

10. Clifton PM. Effect of grape seed extract and quercetin on cardiovascular and endothelial parameters in high-risk subjects. J Biomed Biotechno 2004;2004(5):272-8.

11. Maheswari UM, Rao PG. Antihepatotoxic effect of grape seed oil in rat. Indian J Pharmacol 2004;37(3):179-82.

12. Sreemantula S, Nammi S, Kolanukonda R, Koppula S, Boini KM. Adaptogenic and nootropic activities of aqueous extract of Vitis vinifera (grape seed): An experimental study in rat model. BMC Complement Altern Med 2005;5:1.

13. Vitseva O, Varghese S, Chakrabarti S, Folts JD, Freedman JE. Grape seed and skin extracts inhibit platelet function and release of reactive oxygen intermediates. J Cardiovasc Pharmacol 2005;46(4):445-51.

14. Roy AM, Baliga MS, Elmets CA, Katiyar SK. Grape seed proanthocyanidins induce apoptosis through p53, Bax, and caspase 3 pathways. Neoplasia 2005;7(1):24-36.

15. Kijima I, Phung S, Hur G, Kwok SL, Chen S. Grape seed extract is an aromatase inhibitor and a suppressor of aromatase expression. Cancer Res 2006;66(11):5960-7.

16. Wen W, Lu J, Zhang K, Chen S. Grape seed extract inhibits angiogenesis via suppression of the vascular endothelial growth factor receptor signaling pathway. Cancer Prev Res (Phila) 2008;1(7):554-61.

17. Kim TH, Jeon EJ, Cheung DY, Kim CW, Kim SS, Park SH, et al. Gastroprotective effects of grape seed proanthocyanidin extracts against nonsteroid anti-inflammatory drug-induced gastric injury in rats. Gut Liver 2013;7(3):282-9.

18. Hassan HM. Hepatoprotective effect of red grape seed extracts against ethanol-induced cytotoxicity. Glob J Biotechnol Biochem 2012;7(2):30-7.

19. Saito M, Hosoyama H, Ariga T, Kataoka S, Yamaji N. Antiulcer activity of grape seed extract and procyanidins. J Agric Food Chem 1998;46(4):1460-4.

20. Firdous SM, Neraja K, Debnath R, Singha D, Sravanthi K. Evaluation of antiulcer activity of ethanolic extract of Sechium edule fruits in experimental rats. Int J Pharm Pharm Sci 2012;4(1):374-7.

21. Bickel M. Activity on gastrointestinal tract. In: Vogel GH, Vogel WH, Scholkens BA, Sandow J, Muller G, Vogel WF, editors. Drug Discovery and Evaluation: Pharmacological Assays. $2^{\text {nd }}$ ed. Germany: Springer Publications; 2002. p. 867-72.

22. Ingale AM, Rajendran V, BharatKumar VP. A comparative evaluation of the anti-ulcer activity of the extracts of seed and skin of Vitis vinifera (grape) in wistar albino rats. Int J Clin Diagn Res 2014;2(2):I.

23. Malairajan P, Gopalakrishnan G, Narasimhan S, Veni KJ. Evalution of anti-ulcer activity of Polyalthia longifolia (Sonn.) Thwaites in experimental animals. Indian J Pharmacol 2008;40(3):126-8.

24. Ingale AM, Rajendran V, Kumar VP. A comparative evaluation of the anti-ulcer activity of the extracts of seed and skin of Vitis vinifera. Int J Clin Diagn Res 2014;2(2):1.

25. Mittal R, Bhardwaj RK. Antiulcer agents. In: Gupta SK, editor. Drug Screening Methods. $2^{\text {nd }}$ ed. New Delhi: Jaypee Brothers Medical Publishers (P) ltd.; 2009.

26. Rathnakumar K, Jaikumar S, Sengottuvelu S. Antiulcer activity of Euphorbia hirta against experimentally induced ulcer in rats. Asian J Pharm Res 2013;3(3):121-4.

27. Kumar V, Abbas AK, Fausto N, Aster JC. Robbins and Cotran Pathological Basis of Diseases. $8^{\text {th }}$ ed. Pennsylvania: Elsevier Saunders Publishers; 2010

28. Shi J, Yu J, Pohorly JE, Kakuda Y. Polyphenolics in grape seedsbiochemistry and functionality. J Med Food 2003;6(4):291-9.

29. Ingale AM, Pinnelli VB, Rajendran V. Experimental evaluation of the anti-ulcer activity of the ethanolic extract of grape (Vitis vinifera) seed in wistar albino rats against aspirin plus pylorus ligation induced gastric ulcer model. Int J Basic Clin Pharmacol 2016;5(3):722-7. 
30. Brzozowski T, Konturek PC, DrozdowiczD, Konturek SJ,Zayachivska O, Pajdo R, et al. Grapefruit-seed extract attenuates ethanol-and stressinduced gastric lesions via activation of prostaglandin, nitric oxide and sensory nerve pathways. World J Gastroenterol 2005;11(41):6450-8.
31. Cuevas VM, Calzado YR, Guerra YP, Yera AO, Despaigne SJ, Ferreiro RM, et al. Effects of grape seed extract, vitamin C, and vitamin E on ethanol- and aspirin-induced ulcers. Adv Pharmacol Sci $2011 ; 2011: 740687$ 